Int. J. Electrochem. Sci., 13 (2018) $1869-1878$

International Journal of

ELECTROCHEMICAL

SCIENCE

www.electrochemsci.org

\title{
Phase Diagram and Tin Whisker Growth During Electrodeposition
}

\author{
M. Saitou \\ University of the Ryukyus, Department of Mechanical Systems Engineering, 1 Senbaru Nishihara-cho \\ Okinawa, 903-0213, Japan. \\ *E-mail: saitou@tec.u-ryukyu.ac.jp
}

doi: $10.20964 / 2018.02 .24$

Received: 2 October 2017 / Accepted: 24 November 2017 / Published: 28 December 2017

Using X-ray diffraction patterns of Sn thin films generated by employing rectangular pulse current, a phase diagram was obtained that showed the effects of changes in the deposition temperature and current amplitude on the crystal structure of Sn. A difference was observed between our phase diagram and previously reported solid-solid phase diagram that shows the transition from $\beta$-Sn to $\alpha-S n$. Only the $\beta$-Sn solid phase appeared in the deposition temperature range from 0 to $60{ }^{\circ} \mathrm{C}$. No stable $\alpha$-Sn solid phase below a critical temperature of $13.2{ }^{\circ} \mathrm{C}$ in the solid-solid phase diagram was identified. Scanning electron microscopy observations of the $\mathrm{Sn}$ thin films indicated that $\mathrm{Sn}$ whiskers grew from a smooth Sn surface at an anomalous growth rate in this temperature range. The Sn thin film growth obeyed the Stranski-Krastanov mode.

Keywords: Thin film; $\alpha-S n ; \beta-S n$; Phase transition; Sn whisker; Phase diagram; Anomalous growth rate; Stranski-Krastanov mode

\section{$\underline{\text { FULL TEXT }}$}

(C) 2018 The Authors. Published by ESG (www.electrochemsci.org). This article is an open access article distributed under the terms and conditions of the Creative Commons Attribution license (http://creativecommons.org/licenses/by/4.0/). 